\title{
Effect of heat treatment on tensile behaviour of Ti-6Al-5Zr-0.5Mo-0.25Si alloy
}

\author{
ANIL KUMAR NAG, K V U PRAVEEN and VAKIL SINGH* \\ Department of Metallurgical Engineering, Institute of Technology, Banaras Hindu University, Varanasi 221 005, India
}

MS received 20 August 2005; revised 15 October 2005

\begin{abstract}
Tensile behaviour of the near $\alpha$ titanium alloy, Ti-6Al-5Zr-0.5Mo-0.25Si (LT26A), was investigated in $(\alpha+\beta)$ as well as $\beta$ treated condition, over a wide range of temperature from RT to $823 \mathrm{~K}$. It was observed that there were distinct serrations on the load-elongation curves of the $\alpha+\beta$ treated material at intermediate temperatures from 623 to $723 \mathrm{~K}$. Tensile tests at $673 \mathrm{~K}$ over a wide range of strain rate from 0.052 to $5.60\left(\times 10^{-2}\right) \mathrm{s}^{-1}$ showed negative strain rate sensitivity. Thus, occurrence of DSA was confirmed. It was established from the measured activation energy for DSA that it was essentially controlled by diffusion of the solid solution strengthener silicon in the matrix.
\end{abstract}

Keywords. Titanium alloy LT26A; $\beta$ solution treatment; tensile properties; dynamic strain ageing (DSA).

\section{Introduction}

Indigenously manufactured near- $\alpha$ titanium alloy, LT26A, is closely similar to IMI685, designed for high temperature applications in aero engines up to service temperature of $793 \mathrm{~K}$. It is a medium strength alloy with excellent creep and fatigue properties and reasonable ductility. LT26A has a nominal composition of Ti-6Al$5 \mathrm{Zr}-0 \cdot 5 \mathrm{Mo}-0 \cdot 25 \mathrm{Si}$ and is characterized by predominantly $\alpha$ phase microstructure. Aluminum addition enhances creep resistance at elevated temperature. Solubility of $\beta$ stabilizing element, Mo, is low in $\alpha$ titanium. However, small addition of Mo made to the LT26A alloy is held mainly as solid solution in the $\alpha$ phase and improves tensile strength of the alloy at room and elevated temperatures. Small addition of silicon, also held as solid solution in the $\alpha$ phase, increases tensile strength at all temperatures and creep strength at temperatures above $673 \mathrm{~K}$ (Flower et al 1971). Near- $\alpha$ characteristics of this alloy permit it to be hot worked at $\geq 1323 \mathrm{~K}$ and heat treated in the $\beta$ phase field without the risk of room temperature embrittlement encountered in other titanium alloys processed in this way.

Dynamic strain ageing (DSA) is generally associated with serrated plastic flow and is also known as PortevinLeChatelier effect (PLE). It arises from interactions between diffusing solute atoms and mobile dislocations. Experimentally DSA is manifested by (a) peaks (or plateaus) in the $0.2 \%$ proof stress vs temperature plots, (b) serrated or jerky flow (PLE), (c) negative strain rate sensitivity, (d) occurrence of work hardening peak and

\footnotetext{
*Author for correspondence (vakil@bhu.ac.in)
}

(e) ductility minimum in the plot of ductility vs temperature plot. Occurrence of DSA has been reported by a number of investigators: like in CP titanium (Garde et al 1972), $\beta$ titanium alloys (Zeyfang and Conrad 1971), TiSi alloys (Doner and Conrad 1973) and in several near- $\alpha$ titanium alloys (Assadi et al 1979; Singh and Ramachandra 1985). DSA in titanium alloys has been attributed to interaction between interstitial solute atoms and dislocations (Garde et al 1972), however, other investigators have reported that substitutional elements like $\mathrm{Al}, \mathrm{Zr}$ and Mo cause DSA in $\alpha$ and $\beta$ titanium alloys (Zeyfang and Conrad 1971). In substitutional alloys serrated flow is observed only after a critical strain (McCormick 1972). DSA is known to have strong influence on the extent of uniform elongation. With increase in temperature, while uniform strain tends to decrease, necking strain increases (Garde et al 1972). Near- $\alpha$ alloys are known to exhibit higher creep resistance in the $\beta$ treated condition (Neal 1984). The present investigation was undertaken to characterize tensile behaviour of the near- $\alpha$ titanium alloy, LT26A, following $\beta$ treatment and cooling at different rates.

\section{Experimental}

The experimental alloy, LT26A, was procured from the Defence Metallurgical Research Laboratory (DMRL), Hyderabad, in the form of blanks of square cross section $(15 \times 15 \times 130 \mathrm{~mm})$, supplied by MIDHANI, Hyderabad. The chemical composition of the alloy along with that of IMI685 is given in table 1. It may be seen that while concentration of most of the elements is almost comparable 
Table 1. Chemical composition of the alloys, LT26A and IMI685 (wt.\%).

\begin{tabular}{lcccccccccc}
\hline Alloy & $\mathrm{Al}$ & $\mathrm{Zr}$ & $\mathrm{Mo}$ & $\mathrm{Si}$ & $\mathrm{C}$ & $\mathrm{Fe}$ & $\mathrm{O}$ & $\mathrm{N}$ & $\mathrm{H}$ & $\mathrm{Ti}$ \\
\hline LT26A & $6 \cdot 70$ & $5 \cdot 90$ & $0 \cdot 53$ & $0 \cdot 26$ & $0 \cdot 041$ & $0 \cdot 024$ & $0 \cdot 145$ & $0 \cdot 0017$ & $0 \cdot 003$ & Bal. \\
IMI685 & $6 \cdot 28$ & $5 \cdot 22$ & $0 \cdot 53$ & $0 \cdot 25$ & $0 \cdot 080$ & $0 \cdot 021$ & $0 \cdot 140$ & $0 \cdot 0015$ & 0.003 & Bal. \\
\hline
\end{tabular}

Table 2. $\beta$ heat treatments given to the as-received alloy, LT26A.

\begin{tabular}{lclc}
\hline S1. no. & Designation & \multicolumn{1}{c}{ Solution treatment } & Ageing/stabilization \\
\hline 1. & FC-A & $1323 \mathrm{~K} / 1 \mathrm{~h} /$ furnace cooling & $823 \mathrm{~K} / 24 \mathrm{~h}$ \\
2. & FAC-A & $1323 \mathrm{~K} / 1 \mathrm{~h} /$ forced air cooling & $823 \mathrm{~K} / 24 \mathrm{~h}$ \\
3. & OQ-A & $1323 \mathrm{~K} / 1 \mathrm{~h} /$ oil quenching & $823 \mathrm{~K} / 24 \mathrm{~h}$ \\
4. & WQ-A & $1323 \mathrm{~K} / 1 \mathrm{~h} /$ water quenching & $823 \mathrm{~K} / 24 \mathrm{~h}$ \\
\hline
\end{tabular}

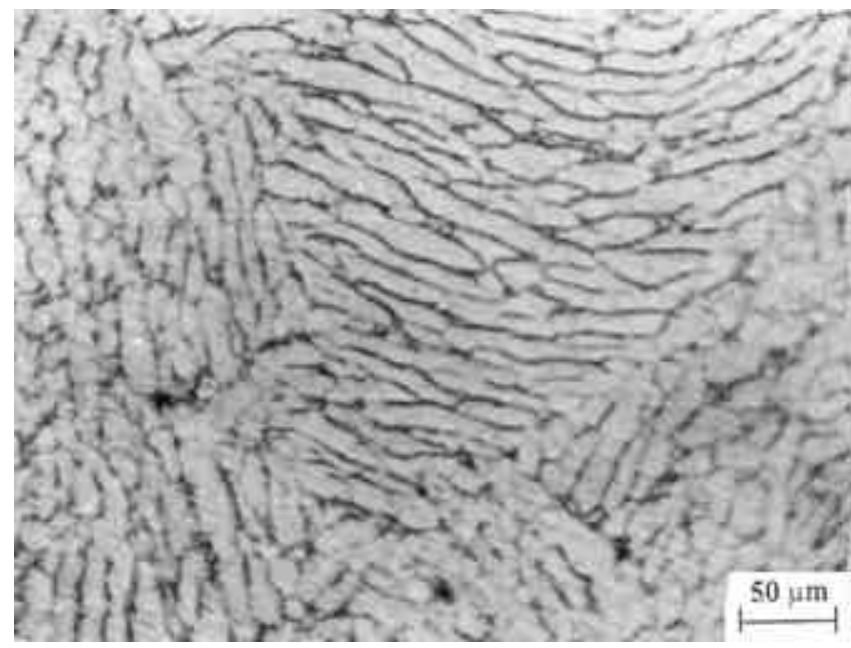

Figure 1. Optical micrograph showing microstructure of the alloy, LT26A, in the as-received condition.

in the two alloys, those of $\mathrm{Al}$ and $\mathrm{Zr}$ is relatively higher in the alloy, LT26A. Carbon content on the other hand is nearly double in the alloy, IMI685, as compared to that of the alloy, LT26A. The as-received condition of this alloy corresponds to $(\alpha+\beta)$ treatment $(1253 \mathrm{~K} / 1 \mathrm{~h})$ and forging. The as-received material was $\beta$ solution treated at $1323 \mathrm{~K}$ and cooled at four different rates (table 2). Standard cylindrical tensile specimens with gauge length, $15.4 \mathrm{~mm}$ and gauge diameter, $4.5 \mathrm{~mm}$ were machined from both as-received and $\beta$ treated material. Tensile tests were performed in the temperature range from RT to $823 \mathrm{~K}$, at a nominal strain rate, $5.6 \times 10^{-4} \mathrm{~s}^{-1}$, using a screw driven INSTRON machine of $50 \mathrm{KN}$ capacity. The desired test temperature was achieved by using a split electric resistance-heating furnace mounted on a stand, attached to the cross head of the INSTRON machine. Tensile tests were carried out for the as-received material at different strain rates of $0 \cdot 052,0 \cdot 10,0 \cdot 56,1.00$ and 5.60 $\left(\times 10^{-2}\right) \mathrm{s}^{-1}$ at $673 \mathrm{~K}$ to establish occurrence of DSA in this alloy.

\section{Results and discussion}

The microstructure of the alloy, LT26A, in the asreceived condition is shown in figure 1 . It shows heavily deformed $\alpha$ grains along with some spheroidized $\alpha$. It was established through VDIS-III image analyser that the average grain size of the $\alpha$ grains was $55 \mu \mathrm{m}$, however, most of the grains lie in the range of $40-70 \mu \mathrm{m}$. The form factor was found to be $0 \cdot 5$, indicating elongated shape of grains. The microstructures of the alloy in $\beta$ solution treated condition followed by four different rates of cooling and ageing/stabilization treatment $(823 \mathrm{~K} / 24 \mathrm{~h})$ are shown in figure 2 . It is obvious that with increasing cooling rate there is refinement in the structure of the transformed $\beta$ phase. While the $\mathrm{FC}-\mathrm{A}$ condition shows Widmanstatten $\alpha$ platelets (figure 2a), FAC-A shows relatively finer Widmanstatten $\alpha$ platelets (figure $2 b$ ), basketweave and acicular $\alpha$ structure may be seen in OQA condition (figure $2 \mathrm{c}$ ) and quenching in water leads to transformation of the $\beta$ phase into fine martensitic platelets of $\alpha$ (figure $2 \mathrm{~d}$ ). It is important to mention that there was no observable effect of the ageing/stabilization treatment $(823 \mathrm{~K}$ for $24 \mathrm{~h})$ on microstructure of all the four differently cooled samples, at optical level. The size of the prior $\beta$ grains was found to lie in the range 700$1600 \mu \mathrm{m}$ and the average grain size was measured to be $1200 \mu \mathrm{m}$.

Tensile data of the alloy, LT26A, in the as-received, FC-A, FAC-A, OQ-A and WQ-A conditions, from RT to $823 \mathrm{~K}$, are recorded in table 3 . The most significant observation made in the load-extension curves was the occurrence of serrations in the flow curve, in the temperature range $623-723 \mathrm{~K}$. The variation of strength and ductility parameters with test temperature for the various conditions is shown in figures $3-6$. It is evident from figures $3 \mathrm{a}, 4$ and 5 that there is flattening of the $0.2 \%$ yield strength (YS) vs temperature plot and there is distinct plateau in the plot of ultimate tensile strength (UTS) vs temperature, in the temperature range 623-723 K. Also, figures $3 \mathrm{~b}$ and 6 depict ductility minimum in $\%$ 

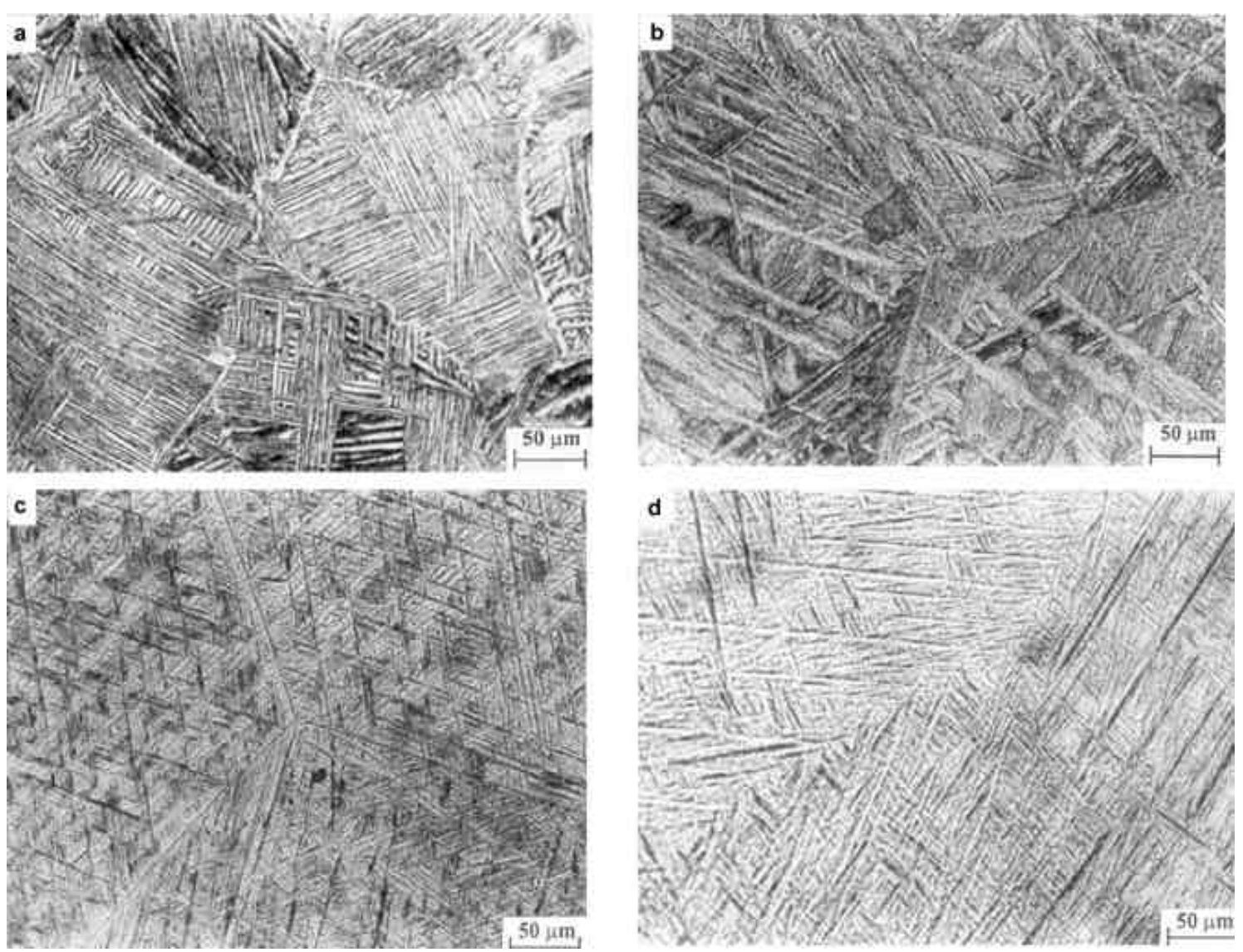

Figure 2. Optical micrographs showing microstructures of the alloy, LT26A, in $\beta$ solution treated and a. FC-A, b. FAC-A, c. OQ-A and $\mathbf{d}$. WQ-A conditions.

Table 3. Tensile properties of the alloy, LT26A, in the as received as well as in the $\beta$ heat treated condition, at different test temperatures.

\begin{tabular}{lcccc}
\hline Designation & Temperature $(\mathrm{K})$ & $0.2 \%$ YS $(\mathrm{MPa})$ & UTS $(\mathrm{MPa})$ & \% elongation \\
\hline As-received & $\mathrm{RT}$ & 884 & 941 & $11 \cdot 0$ \\
& 473 & 605 & 709 & $10 \cdot 0$ \\
& 573 & 544 & 657 & $13 \cdot 0$ \\
& 623 & 505 & 617 & $11 \cdot 5$ \\
& 673 & 494 & 611 & $12 \cdot 5$ \\
& 723 & 492 & 628 & $13 \cdot 0$ \\
& 773 & 460 & 578 & $14 \cdot 5$ \\
FC-A & 823 & 453 & 567 & $14 \cdot 0$ \\
& $\mathrm{RT}$ & 869 & 924 & $6 \cdot 0$ \\
& 573 & 485 & 574 & $7 \cdot 5$ \\
FAC-A & 673 & 472 & 537 & $8 \cdot 0$ \\
& 793 & 429 & 509 & $10 \cdot 5$ \\
& $\mathrm{RT}$ & 902 & 976 & $7 \cdot 5$ \\
& 573 & 552 & 663 & $9 \cdot 5$ \\
OQ-A & 673 & 546 & 629 & $7 \cdot 5$ \\
& 793 & 509 & 595 & $11 \cdot 0$ \\
& $\mathrm{RT}$ & 1006 & 1089 & $7 \cdot 0$ \\
& 573 & 672 & 818 & $7 \cdot 0$ \\
WQ-A & 673 & 654 & 796 & $8 \cdot 2$ \\
& 793 & 605 & 733 & $11 \cdot 5$ \\
& $\mathrm{RT}$ & 1026 & 1094 & $4 \cdot 0$ \\
& 573 & 657 & 812 & $6 \cdot 5$ \\
& 673 & 672 & 826 & $5 \cdot 7$ \\
& 793 & 617 & 812 & $14 \cdot 0$ \\
\hline
\end{tabular}


elongation vs temperature plots. These observations suggest occurrence of DSA in the range of temperature from $623-723 \mathrm{~K}$. From figures 4 and 5 it is clear that the WQ-A

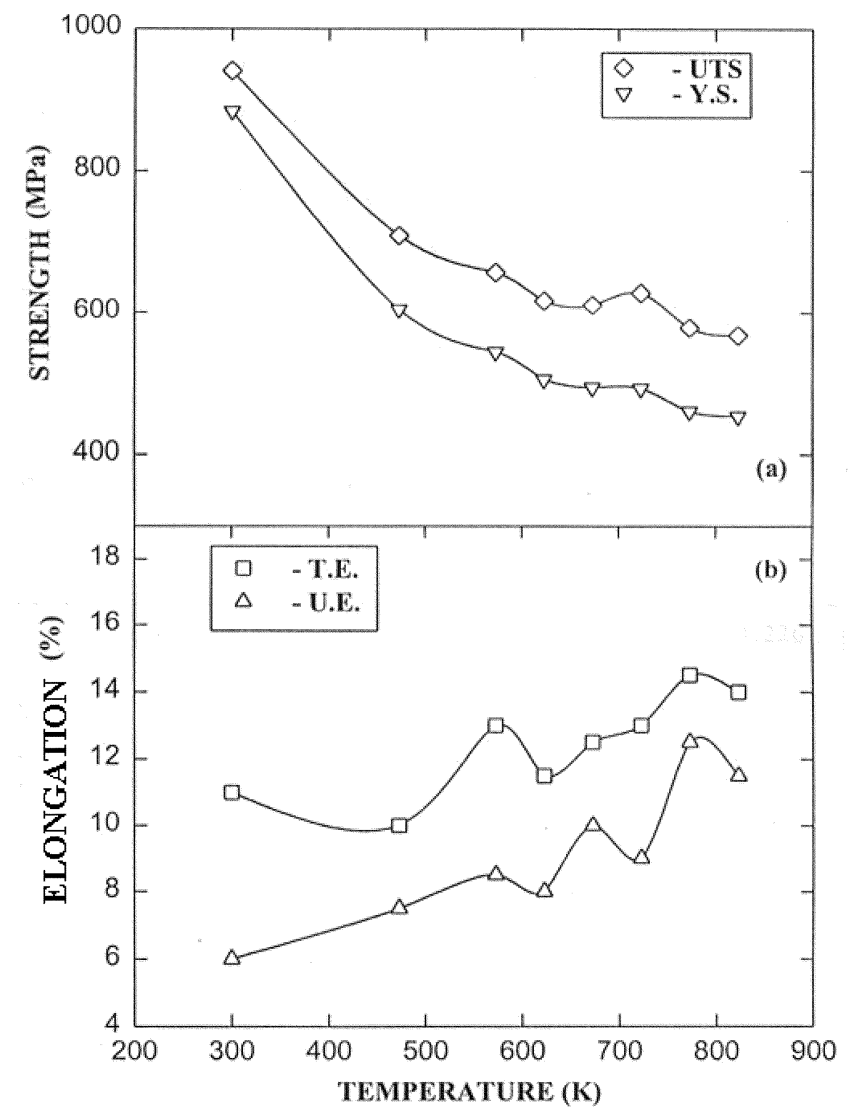

Figure 3. Variation of (a) strength and (b) ductility parameters with test temperature in the as-received condition of the alloy, LT26A.

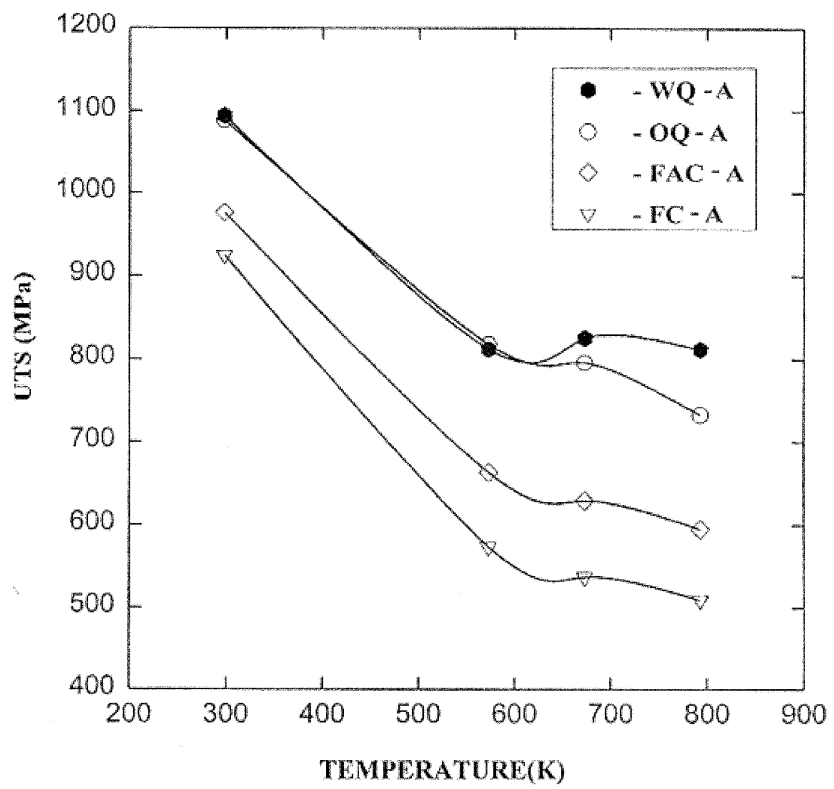

Figure 4. Variation of UTS with test temperature of the alloy, LT26A, in $\beta$ solution treated conditions. condition shows superior properties over other conditions especially above $673 \mathrm{~K}$, followed by OQ-A, FAC-A and FC-A. Based on these observations it may be inferred that increase in cooling rate leads to improvement in tensile properties of this alloy, in the $\beta$ solution treated condition. Figures 7-11 show SEM fractographs of the specimens tested in tension at room temperature as well as $793 \mathrm{~K}$. Fracture characteristics of the as-received as well as $\beta$ treated samples are almost similar at RT and $793 \mathrm{~K}$. Dimples, the nature of which, however, differs

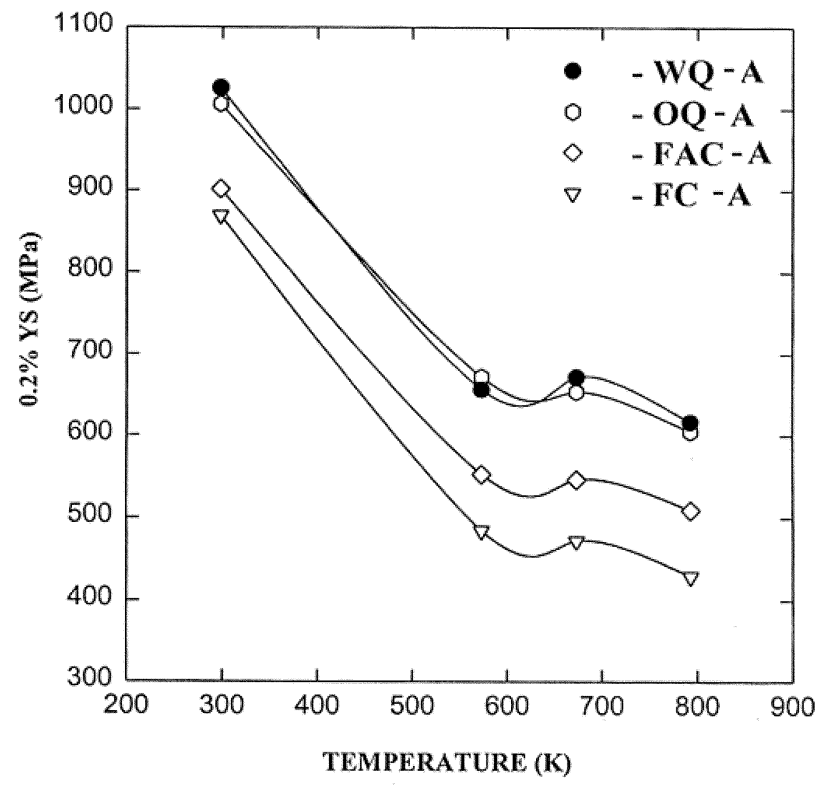

Figure 5. Variation of $0.2 \%$ YS with test temperature of the alloy, LT26A, in $\beta$ solution treated conditions.

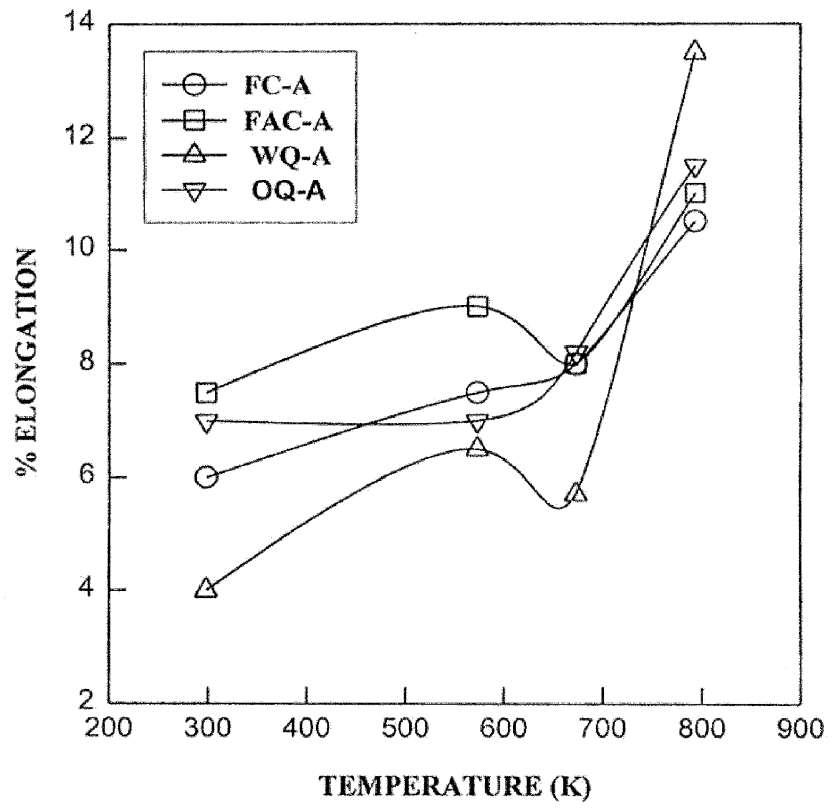

Figure 6. Variation of \% elongation with test temperature of the alloy, LT26A, in the $\beta$ solution treated and aged conditions. 

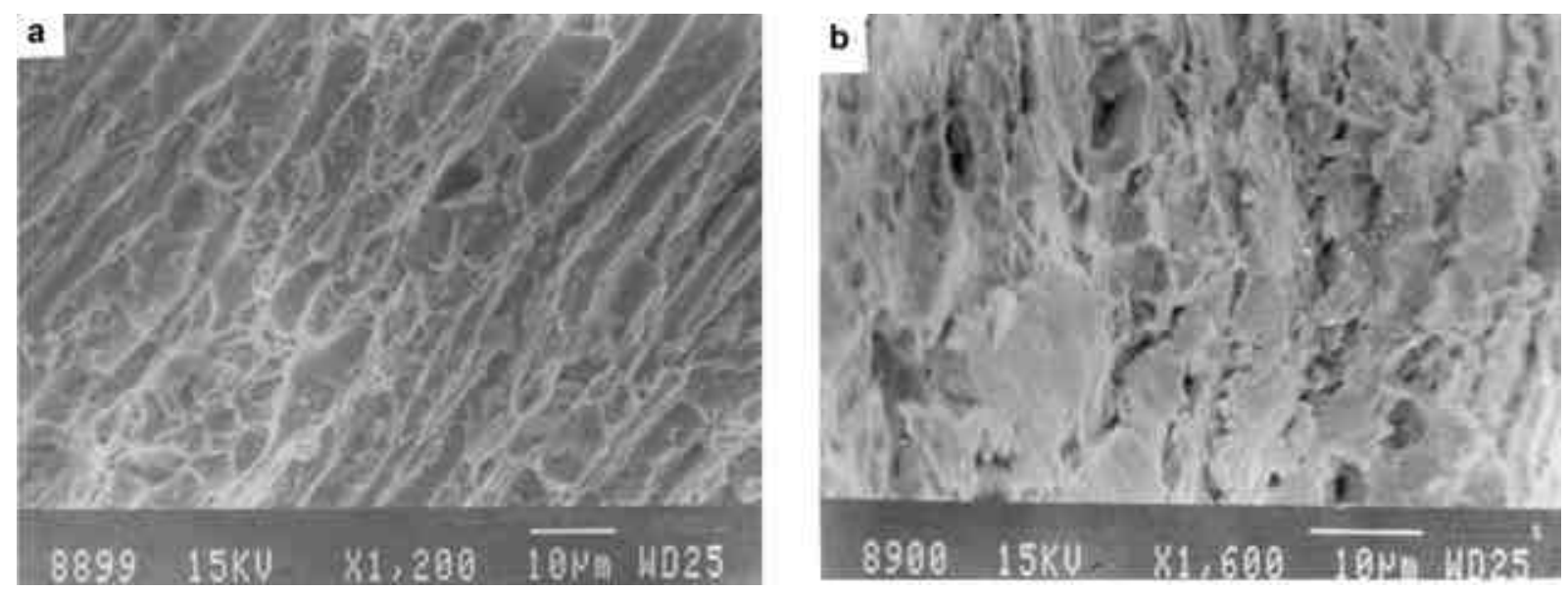

Figure 7. SEM fractographs showing fracture characteristics of the alloy, LT26A, in the as-received condition, tested in tension at a. RT and b. $793 \mathrm{~K}$.

Table 4. Tensile properties of the alloy, LT26A, in the as-received condition, at $673 \mathrm{~K}$, at different strain rates.

\begin{tabular}{lcccccc}
\hline S1. no. & $\begin{array}{c}\text { Strain rate } \\
\times 10^{-2}\left(\mathrm{~s}^{-1}\right)\end{array}$ & $\begin{array}{c}0 \cdot 2 \% \mathrm{YS} \\
(\mathrm{MPa})\end{array}$ & $\begin{array}{c}\text { UTS } \\
(\mathrm{MPa})\end{array}$ & $\begin{array}{c}\% \\
\text { elongation }\end{array}$ & UTS/YS & $\begin{array}{c}\varepsilon_{\mathrm{c}} \\
\left(\times 10^{-2}\right)\end{array}$ \\
\hline 1. & $0 \cdot 052$ & 542 & 659 & $12 \cdot 3$ & 1.216 & 1.14 \\
2. & $0 \cdot 100$ & 511 & 636 & 13.9 & 1.244 & $0 \cdot 78$ \\
3. & $0 \cdot 560$ & 493 & 611 & 12.5 & 1.226 & 1.46 \\
4. & 1.000 & 514 & 654 & $12 \cdot 0$ & 1.272 & 1.56 \\
5. & 5.600 & 490 & 620 & $12 \cdot 3$ & 1.265 & 3.08 \\
\hline
\end{tabular}

Table 5. Effect of test temperature on various work hardening parameters of the alloy, LT26A, in the as-received condition.

\begin{tabular}{lcccccc}
\hline S1. no. & Temperature $(\mathrm{K})$ & UTS/YS & $10^{3} \times \theta / E$ & $n$ & $K$ & $\varepsilon_{\mathrm{c}} \times 10^{-2}$ \\
\hline 1. & $\mathrm{RT}$ & 1.064 & 3.55 & 3.6 & 1091 & - \\
2. & 473 & 1.172 & 5.50 & 6.1 & 897 & - \\
3. & 573 & 1.208 & 6.31 & 6.8 & 819 & - \\
4. & 623 & 1.222 & 6.72 & 7.4 & 790 & 2.76 \\
5. & 673 & 1.238 & 7.37 & 7.2 & 762 & 1.46 \\
6. & 723 & 1.276 & 7.60 & 8.6 & 840 & 1.06 \\
7. & 773 & 1.256 & 5.60 & 7.7 & 740 & - \\
8. & 823 & 1.251 & 4.63 & 8.0 & 747 & - \\
\hline
\end{tabular}

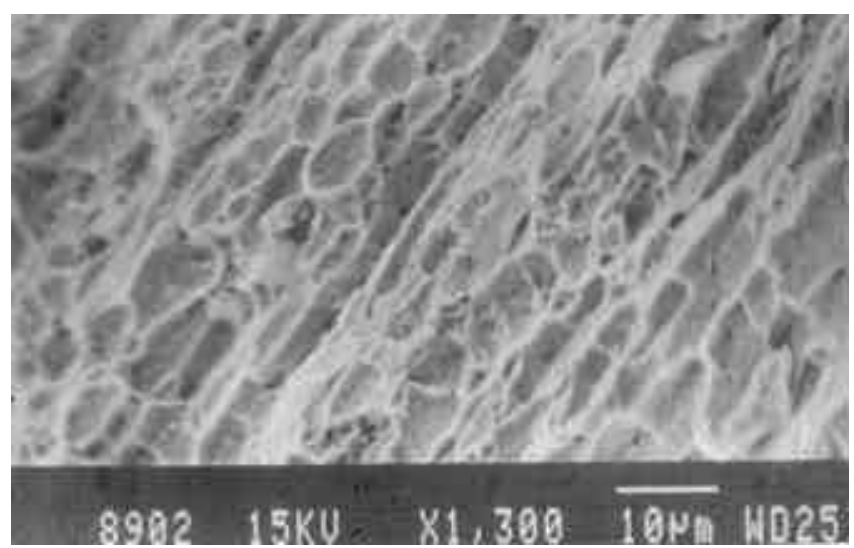

Figure 8. SEM fractograph showing fracture characteristics of the alloy, LT26A, in the FC-A condition, tested in tension at $793 \mathrm{~K}$. slightly from one to other fractograph, characterize fracture behaviour in all the cases. While the specimens tested at room temperature show long and shallow dimples, generally called flutes, those tested at $793 \mathrm{~K}$ show equiaxed and deep dimples, in all the conditions. Thus, there is no obvious change in the mode of fracture in different microstructural conditions. However, there is change in the morphology of the dimples with change in the test temperature. The observed change in the shape of dimples from elongated to equiaxed is in accordance with the observed increase in ductility at higher temperature.

Strain rate dependence of $0 \cdot 2 \%$ YS and UTS was also examined for the as received material, by conducting tensile tests at different strain rates at $673 \mathrm{~K}$, where the serrations were more prominent. The data are presented in table 4 . The variation of $0 \cdot 2 \%$ YS and UTS with strain 

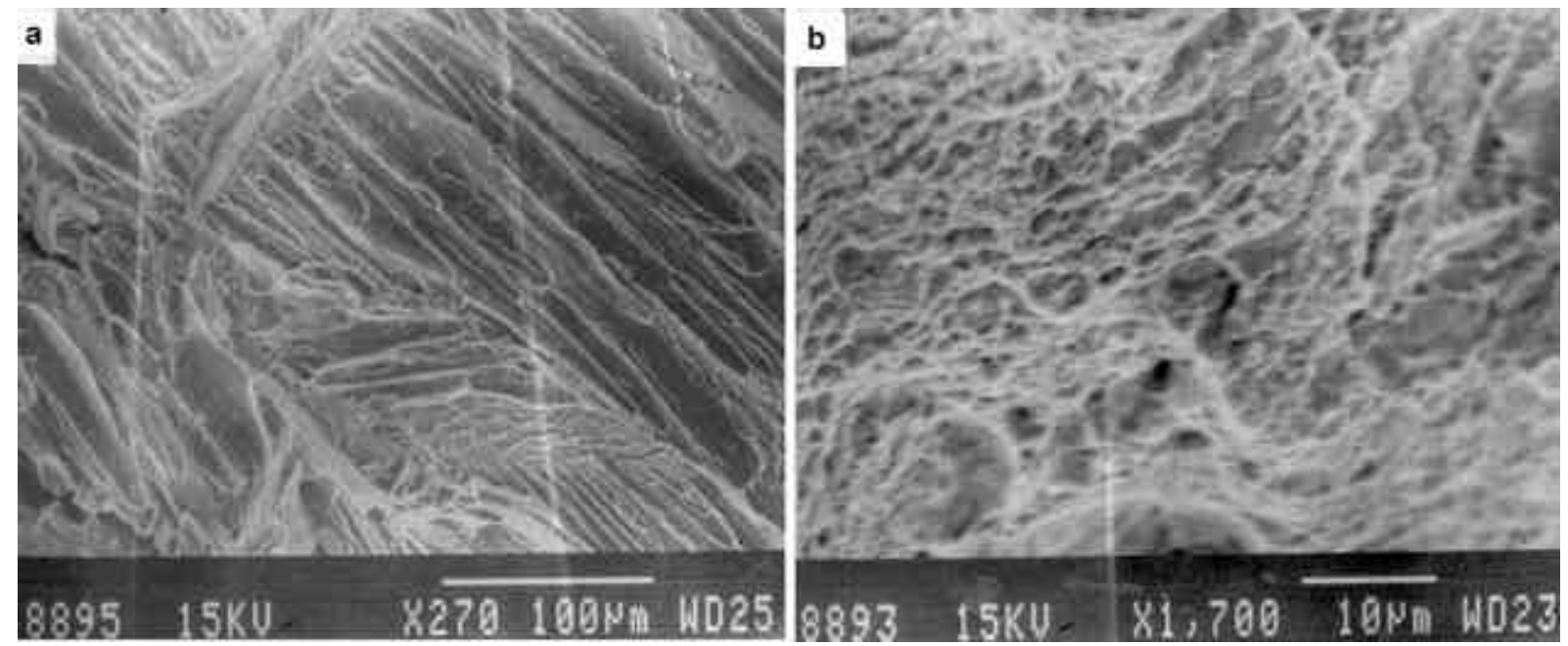

Figure 9. SEM fractographs showing fracture characteristics of the alloy, LT26A, in the FAC-A condition, tested in tension at a. RT and b. $793 \mathrm{~K}$.
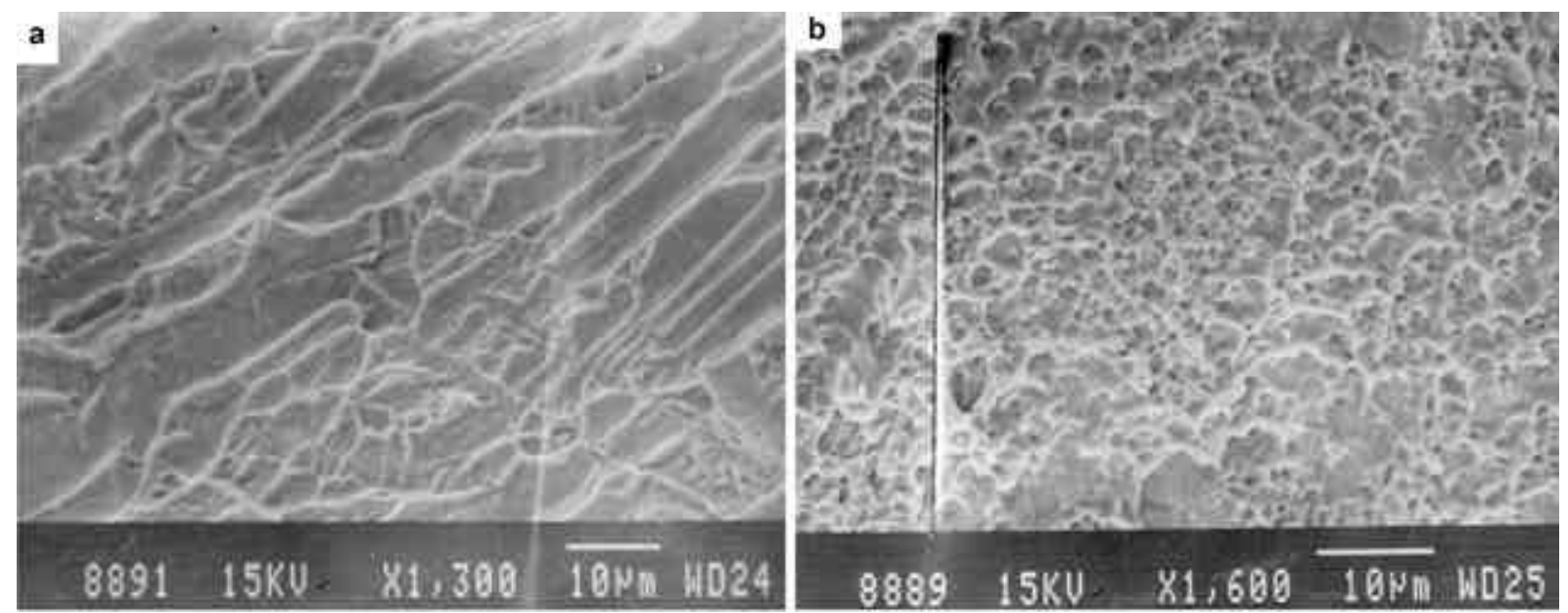

Figure 10. SEM fractographs showing fracture characteristics of the alloy, LT26A, in the OQ-A condition, tested in tension at a. RT and b. $793 \mathrm{~K}$.
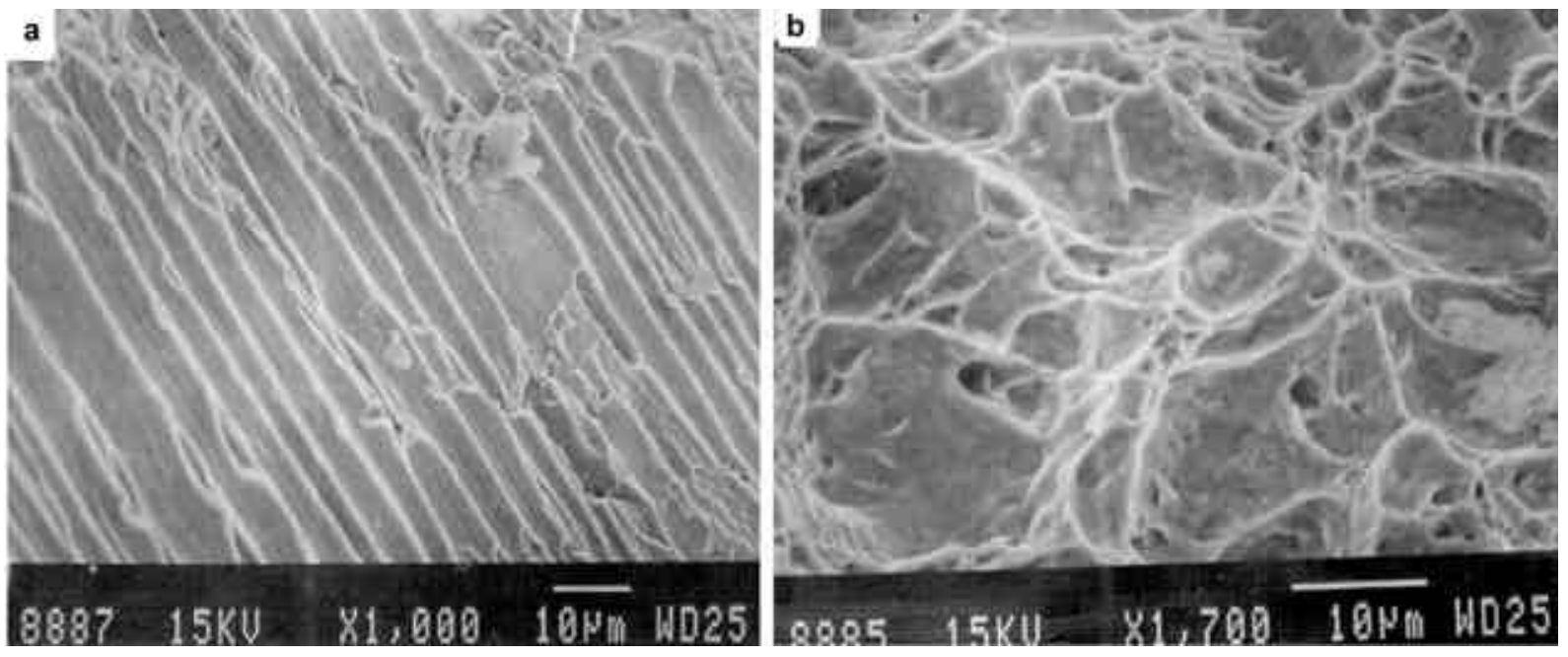

Figure 11. SEM fractographs showing fracture characteristics of the alloy, LT26A, in the WQ-A condition, tested in tension at a. RT and b. $793 \mathrm{~K}$. 
rate, at $673 \mathrm{~K}$, is shown in figure 12 . It is obvious that the strength parameters decrease with increase in strain rate and thus there is negative strain rate sensitivity in this alloy at $673 \mathrm{~K}$, which is one of the most important characteristics of DSA. Temperature dependence of work hardening rate $(\theta=d \sigma / d \varepsilon)$ is illustrated in figure 13 and the data are presented in table 5. It is obvious that the rate of work hardening increases with test temperature to

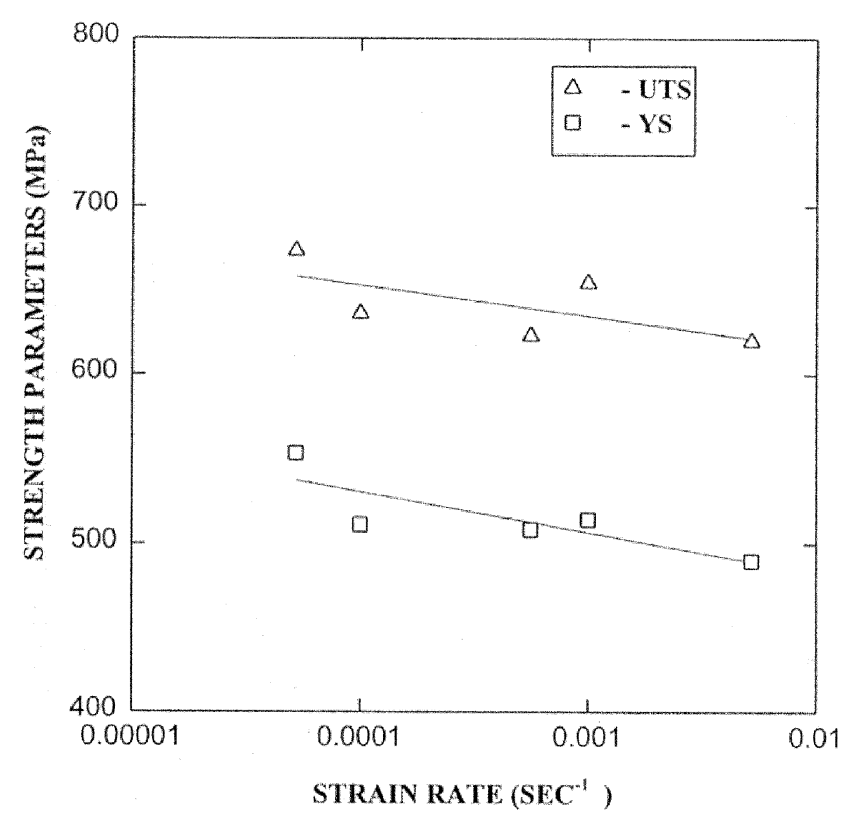

Figure 12. Variation of UTS and $0.2 \%$ YS with strain rate, for the alloy, LT26A, in the as-received condition.

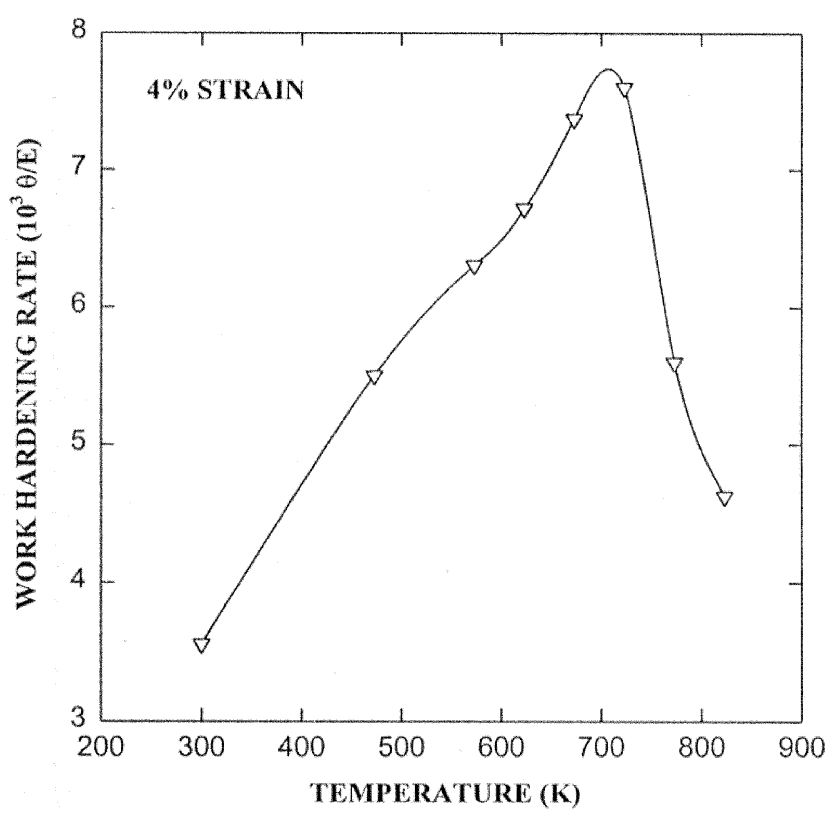

Figure 13. Variation of work hardening rate $\left(10^{3} \times \theta / E\right)$ with test temperature in the as received condition of the alloy, LT26A. reach a peak value in the expected range of temperature for DSA and decreases rapidly at higher temperatures. The work hardening peak may be attributed to occurrence of DSA (Rodriguez 1984; Senkov and Jonas 1996). Several investigators (Garde et al 1972; Senkov and Jonas 1996) have observed DSA in CP titanium and suggested that interstitial elements like carbon, oxygen and nitrogen are responsible for the occurrence of DSA, based on activation energies for diffusion of these elements in $\alpha$ titanium being comparable to activation energy for DSA. In line with these observations, activation energy for DSA in the alloy, LT26A, was calculated and compared with those of various solute elements. Activation energy for DSA was estimated from the measurement of strain rate dependence and temperature dependence of critical strain $\left(\varepsilon_{\mathrm{c}}\right)$, the strain for the onset of serrations, as shown in figure 14 and using the relation (McCormick 1972):

$$
\varepsilon_{\mathrm{c}}^{m+\beta}=K \varepsilon \exp (Q / R T),
$$

where, $Q$ is activation energy for the onset of serrated flow, $R$ the gas constant, $T$ the temperature, $K$ a constant,
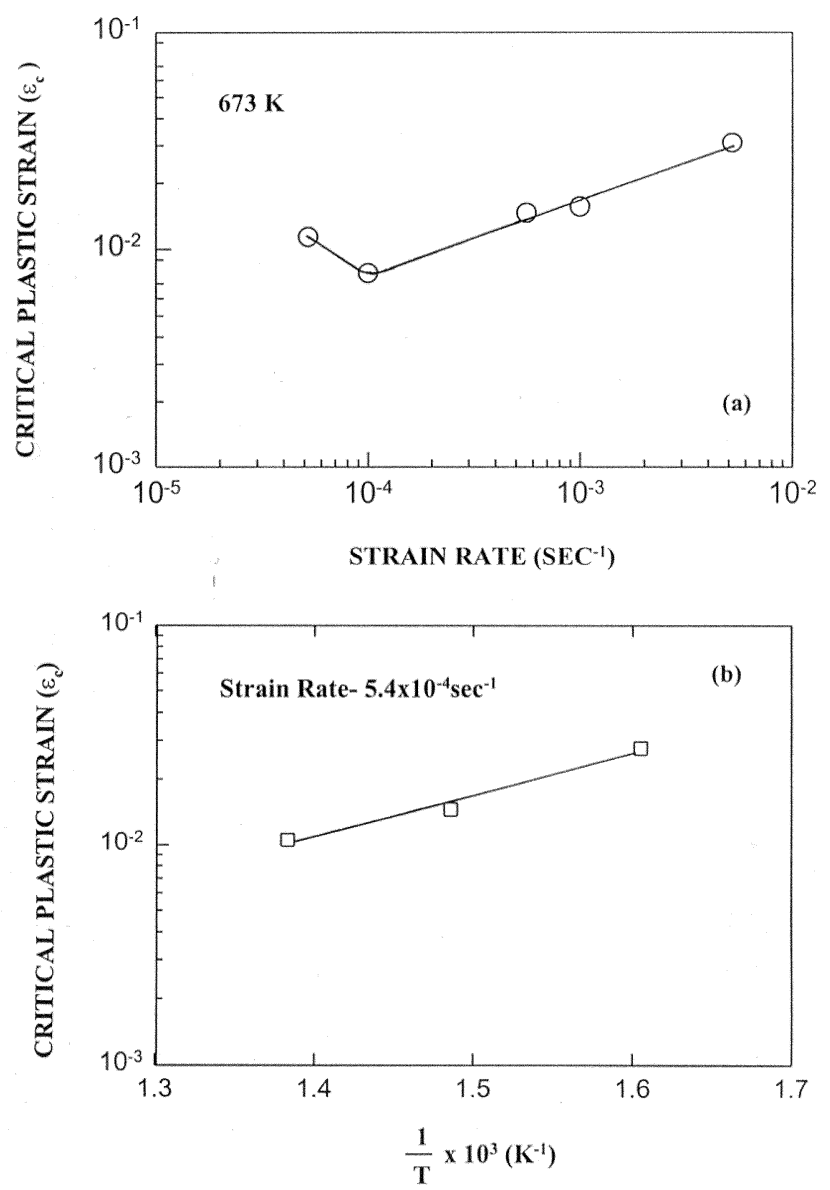

Figure 14. (a) Variation of $\varepsilon_{\mathrm{c}}$ with strain rate and (b) variation of $\varepsilon_{\mathrm{c}}$ with $1 / T$, for the as-received condition of the alloy, LT26A. 
Table 6(a). Activation energy for diffusion of different elements in $\alpha$ titanium.

\begin{tabular}{|c|c|c|c|}
\hline Sl. no. & Element & $\mathrm{Q}(\mathrm{kJ} / \mathrm{mol})$ & References \\
\hline 1. & $\mathrm{H}$ & $46 \cdot 1$ & Kitada and Koda (1969) \\
\hline 2. & $\mathrm{O}$ & $200 \cdot 9$ & David et al (1979) \\
\hline 3. & $\mathrm{~N}$ & $228 \cdot 2$ & Senkov and Jonas (1996) \\
\hline 4. & $\mathrm{C}$ & $182 \cdot 1$ & Senkov and Jonas (1996) \\
\hline 5. & $\mathrm{Fe}_{\perp}$ & $144 \cdot 2$ & Senkov and Jonas (1996) \\
\hline 6. & $\mathrm{Fe}_{\|}^{+}$ & $112 \cdot 3$ & Senkov and Jonas (1996) \\
\hline 7. & $\mathrm{Ti}^{\mathrm{M}}$ & $192 \cdot 8$ & Herzig et al (1991) \\
\hline 8. & $\mathrm{Si}$ & $105 \cdot 1$ & Raisanen and Keinonen (1986) \\
\hline 9. & Al & $156 \cdot 3$ & Senkov and Jonas (1996) \\
\hline 10 . & $\mathrm{Nb}$ & $130 \cdot 3$ & Pontau and Lazarus (1979) \\
\hline
\end{tabular}

Table 6(b). Calculated values of $m+\beta$ and $Q$.

\begin{tabular}{lc}
\hline$m+\beta$ & $Q(\mathrm{~kJ} / \mathrm{mol})$ \\
\hline 2.9188 & 105.47 \\
\hline
\end{tabular}

and the exponent, $m+\beta$ is related to the vacancy concentration, $C$ and the density of mobile dislocations $\left(\rho_{\mathrm{m}}\right)$. The value of $m+\beta$, calculated from the slope of the plot of $\varepsilon_{\mathrm{c}}$ vs strain rate (figure $14 \mathrm{a}$ ), is found to be 2.918 . The exponent, $m+\beta$, is often used to identify the mechanisms responsible for serrated flow behaviour (Rodriguez 1984; Rodriguez and Venkadesan 1995). General convention is that if the value of $m+\beta$ is in the range $0 \cdot 5-1$, interstitial solutes are responsible for strain ageing, whereas when $m+\beta$ is in the range $2-3$, substitutional solutes are responsible. As the value of $m+\beta$ of the present investigation lies in the range $2-3$, substitutional solutes should be responsible for strain ageing. The temperature dependence of $\varepsilon_{\mathrm{c}}$ measured at a nominal strain rate of $5.4 \times 10^{-4} \mathrm{~s}^{-1}$ is shown in figure $14 \mathrm{~b}$. The apparent activation energy, calculated from the slope of $\varepsilon_{\mathrm{c}}$ vs $1 / T$ plot, according to (1), by using $m+\beta$ value of $2 \cdot 918$, is $105.47 \mathrm{~kJ} / \mathrm{mole}$.

The data for the activation energy for DSA, obtained in the present investigation, with the activation energies for diffusion of the alloying elements in $\alpha$ titanium are presented in table 6 . It is evident from the data that the activation energy for diffusion of silicon in $\alpha$ titanium is in good agreement with the calculated activation energy for DSA and therefore, it may be inferred that diffusion of the substitutional solute silicon is responsible for the occurrence of DSA in this temperature range of 623-723 K. This observation is in agreement with the earlier observations made by several investigators (Assadi et al 1979; Ramachandra 1985), who have attributed DSA to silicon in solid solution and found that the tendency for DSA was reduced due to silicide precipitation, because of depletion of silicon from the solid solution. The activation energy for diffusion of iron in $\alpha$ titanium is also very close to the calculated activation energy for DSA, however, it appears to be unlikely to cause DSA because the amount of $\mathrm{Fe}$ in this alloy is much lower in comparison to silicon.

\section{Conclusions}

The following conclusions are drawn from the present investigation:

(I) The near $\alpha$ titanium alloy, LT26A, exhibits dynamic strain ageing in the temperature range, 623-723 $\mathrm{K}$, in all the heat-treated conditions.

(II) With increase in cooling rate, tensile properties of the $\beta$ solution treated samples increase. Best properties are exhibited in the WQ-A condition.

(III) The $m+\beta$ value calculated at $673 \mathrm{~K}$ lies in the range of $2-3$, thus it may be inferred that substitutional solutes are responsible for DSA in this alloy.

(IV) The activation energy for DSA, evaluated at $673 \mathrm{~K}$, is quite close to the activation energy for diffusion of silicon in $\alpha$ titanium.

(V) Silicon, a solid solution strengthener, is responsible for DSA behaviour exhibited by this alloy in the temperature range $623-723 \mathrm{~K}$.

\section{References}

Assadi A T K, Flower H M and West D R F 1979 Metals Tech. 68

David D, Gracia E A, Lucas X and Beranger G 1979 J. Less Common Metals 6551

Doner M and Conrad H 1973 Metall. Trans. 42809

Flower H M, Swann P R and West D R F 1971 Metall. Trans. 2 3289

Garde A M, Santhanam A T and Reed-Hill R E 1972 Acta Mater. 20215

Herzig C, Willecke R and Vieregge K 1991 Philos. Mag. 63 949

Kitada M and Koda S 1969 Scr. Metall. 3583

McCormick P G 1972 Acta Metall. 20351

Neal D F 1984 Proc. fifth international conference on "Titanium science and technology" (eds) G Iutjering et al (Munich: DGM) 4 p. 2419

Pontau A E and Lazarus D 1979 Phys. Rev. B19 4027

Raisanen J and Keinonen J 1986 Appl. Phys. Letts 49773

Ramachandra C 1985 Characterization and effect of silicides on the mechanical behaviour of Ti alloys IMI685 and VT9, Ph D Thesis, Banaras Hindu University, Varanasi

Rodriguez P 1984 Bull. Mater. Sci. 6653

Rodriguez P and Venkadesan S 1995 Key Engg. Mater. 103257

Senkov O N and Jonas J 1996 J. Met. Mater. Trans. A27 1877

Singh V and Ramachandra C 1985 Key Engg. Mater. A8 185

Zeyfang R and Conrad H 1971 Acta Metall. 19985 